\section{International Journal of Engineering Research and \\ Advanced Technology (IJERAT)}

DOI: $\underline{\text { 10.31695/IJERAT.2019.3456 }}$
E-ISSN : 2454-6135

Volume.5, Issue 6

June -2019

\title{
INFUSION PUMP WITH NEBULIZER UNIT FOR HEALTHCARE
}

\author{
Vasu. $S^{1}$ and Jithendra P R Nayak ${ }^{2}$ \\ ${ }^{1}$ P.G. Scholar and ${ }^{2}$ Assistant professor \\ GMIT Bharathi Nagar, Maddur \\ Karnataka, India
}

\begin{abstract}
This project involves the designing of a medical device that supports two different drug delivery systems. One of which is a liquid injection, that can be intravenous or through the digestive tract. The Second part involves another drug delivery system which helps us inject drugs into the lungs in the gaseous phase. Infusion pumps are basically syringing control devices that are used for the slow injection of liquid food or drugs. The injection pump we attempt to design in this project is a simple robot that uses a motor to control the piston of the syringe with precision. In this project, the nebulizer uses a piezoelectric disk that is vibrated at an ultrasonic resonating frequency that ejects the liquid into the atmosphere as very small Droplets.
\end{abstract}

Key Words: Nebulizer unit, Pump, Injection, IDE

\section{INTRODUCTION}

In a country with a large population like India providing quality and cheap healthcare comes with a lot of obstacles. In this project we have tried to tackle one such obstacle by trying to replicate medical equipment in the simplest and cheapest methods.

This project involves the designing of a medical device that supports two different drug delivery systems. One of which is liquid injection, that can be intravenous or through the digestive tract. The Second part involves another drug delivery system which helps us inject drugs into the lungs in gaseous phase.

\section{DESIGN METHODOLOGY}

We will use a stepper motor with a L298D motor driver which will run a simple mechanical setup suitable to drive the syringe. The mechanical setup consists of a circular crank with a rod attached close to its circumference, the stepper motor's shaft acts as the driving shaft for the circular crank. The end of the rod connected to the shaft is connected to the syringe piston. The stepper motor's rotational motion is translated to linear motion and used to drive the syringe pump. The Second part involves another drug delivery system which helps us inject drugs into the lungs in gaseous phase. The drug can be intended to deposit drugs in the lungs directly or be used to inject the blood stream with the drug through the lungs. (The air we inhale is absorbed by the blood). The existing system mainly has a bulky air compressor module that runs on $\mathrm{AC}$ current. But we use a piezo electric disk to vaporize the liquid. Piezo electric materials produce electric signals when exposed to mechanical energy. The reverse also can be achieved. It consists of a mechanically vibrating

Plate perforated with micro- size apertures. The mesh is assembled with the metallic holder and piezoelectric ring actuator. During operation the liquid is in contact with the top surface of the mesh, which is excited into out-of-plane vibration by the laterally vibrating actuator. Alternating vibration of the mesh builds up alternating pressure in the liquid 
in the vicinity of the mesh pushing the liquid through the apertures and ejecting aerosol droplets on the other side of the mesh.

\section{BLOCK DIAGRAM}

\subsection{Working Principle}

The figure 1shows the flow chart of the proposed model. The works on the process of combination of hardware and mechanism concept for drug supply for patients. The final style may be a combination of section central management unit consists of Atmega328p microcontroller. The microcontroller is interfaced with alphanumeric display and computer keyboard for computer program. The user are ready to enter the specified inputs, initialize the device and stop it just in case of emergency. The microcontrollers can management the ability through the stepper motor and therefore the supersonic electricity device. Once the infusion pump is needed to run, the microcontroller drives the stepper motor through the motive force at the specified speed. We used the previous standardization.

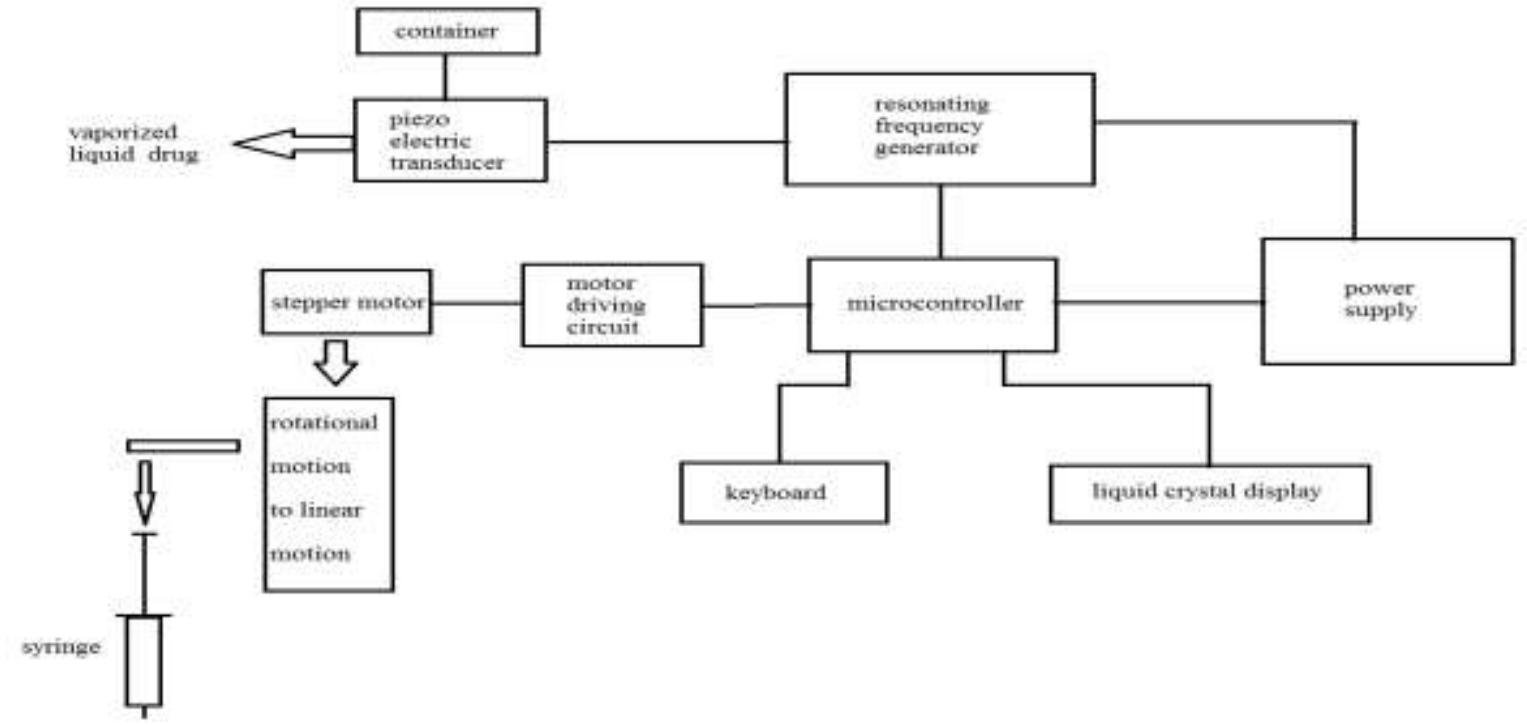

The figure 1shows the flow chart of the proposed model

\subsection{Application}

- Injection of insulin and other hormones

- Injection of antibiotics

- Administrating Pain relievers

- Administrating Anesthesia

- In chemotherapy

- Bronchial asthma

\subsection{OBJECTIVES}

- To design an efficient two in one drug delivery system

- The design must be simple to manufacture and use

- The design must be compact and portable

- The overall manufacturing cost must be less, thus making it cheaper in market 
- The design is simple as the objective suggested

- The product is compact considering the availability two drug delivery systems in one device.

- The product is very much cost effective

- The device successfully works as a two in one drug delivery system

\section{WORKING MODEL}

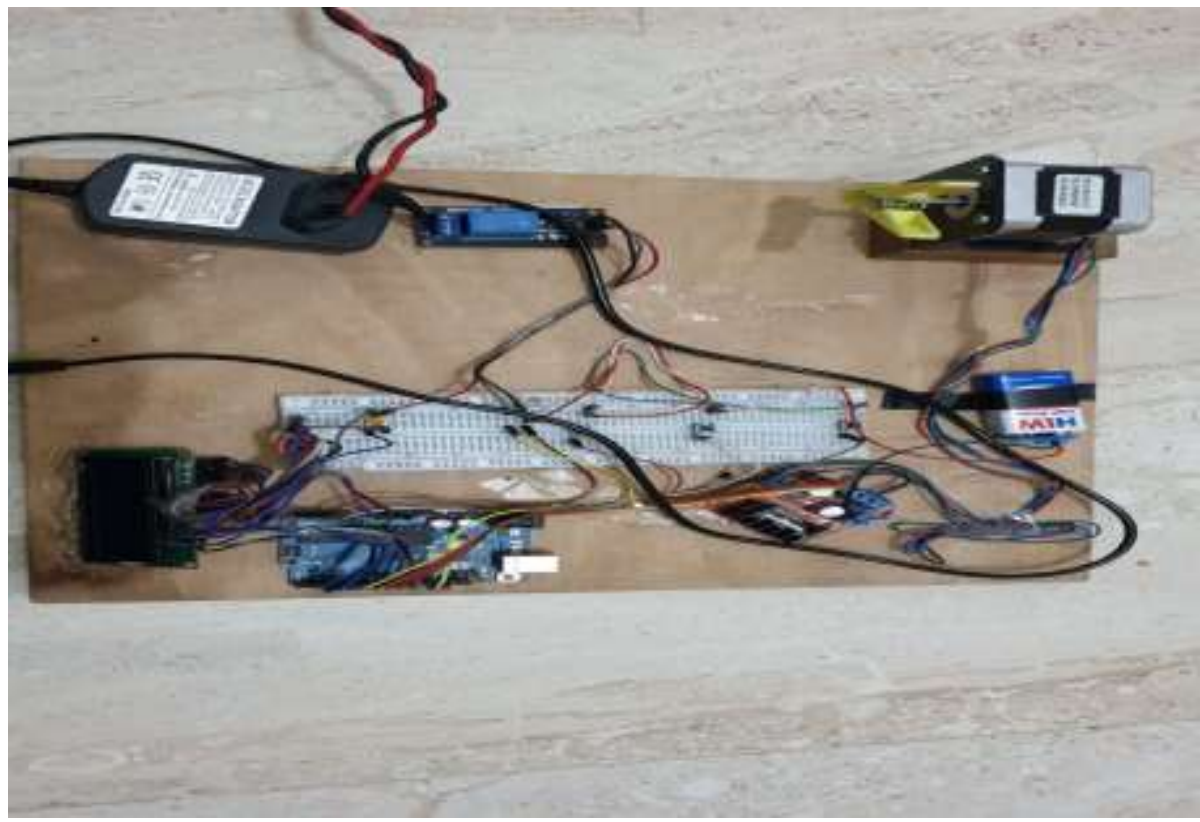

Figure 2. Working model of Nebulizer.

\section{STAGE 1:}

Start device and display initial message

"1.infusion pump

2. Nebulizer"

\section{STAGE 2:}

If selected infusion pump go to screen 2 and display modes

"5 $\mathrm{ml} / \mathrm{min} 10 \mathrm{ml} / \mathrm{min} 15 \mathrm{ml} / \mathrm{min}$ "

\section{STAGE 3:}

Start the infusion pump motor according to the selected mode and show stop option.

\section{STAGE 4:}

If nebulizer is selected display screen 3 with

"Start stop"

\section{STAGE 5:}

Start and stop the nebulizer as required

\section{STAGE 6:}

Reset button should redirect the display to first screen

\section{STAGE 7:}

Power off 
The prototype has many applications in the field of medication from administration of insulin and other hormones, treating immunocompromised patients to contributing in chemotherapy for cancer patients.

\section{RESULT AND GRAPH}

Figure 3 shows the Performance graphs of Nebulizer. The design proves too effective in delivering drug both in liquid and gaseous phase.

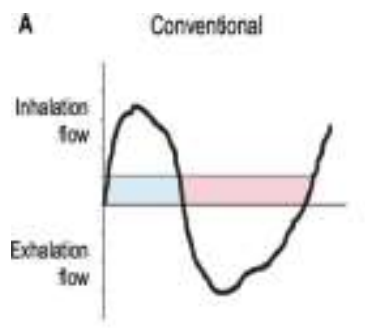

D

B Breatr-activated (mecharical)

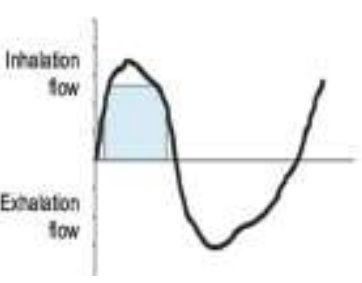

Venturí
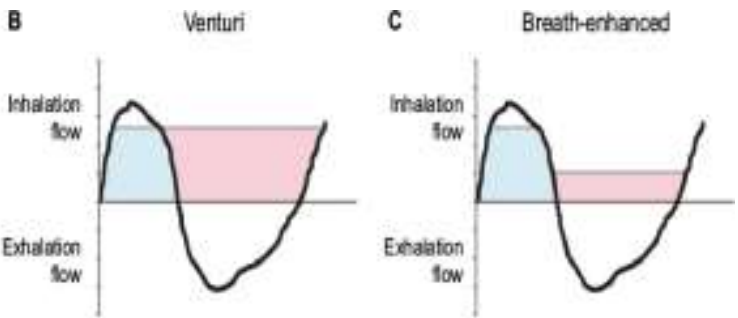

E Breath-activated (electronic)

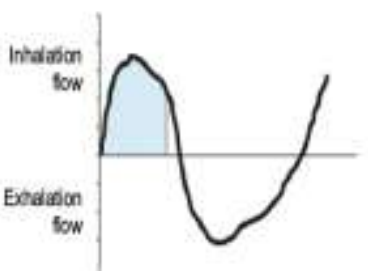

Figure 3 Performance graphs of Nebulizer.

The infusion pump works in different speed modes. The nebulizer is able to convert the liquid medicine to vapor phase.

\section{CONCLUSION}

This project proposed to build a two-way drug delivery system which was efficient, compact, simple in design and inexpensive. The proposed methodology was to use a stepper motor and mechanical setup to drive the piston of the syringe at required speeds. Along with this, a vibrating mesh nebulizer which could convert liquid phase drugs to vapor phase. This gave us a device that performed two-way drug delivery that is in vapor phase and liquid phase. The results of the project showed how the device performed in both categories, where the liquid was injected out of the syringe at required speed. And the vibrating mesh nebulizer converted the liquid to vapors. The combination of the two systems proved to be compact, cheap and simple to manufacture.

\section{REFERENCES}

1. Design and Implementation of Low Cost Smart Syringe Pump for Telemedicine and Healthcare published by Md. Rakibul Islam, Rushdi Zahid Rusho, Sheikh Md. Rabiul Islam, Department of Electronics and Communication Engineering Khulna University of Engineering \& Technology at 2019 International Conference on Robotics, Electrical and Signal Processing Techniques (ICREST) .

2. Designing of Microcontroller based Syringe Pump with Variable and Low Delivery Rates for the Administration of Small Volumes published by Muhammad Ahmed Khan Electrical Engineering \& Information Technology , Osama Mazhar Computer Vision and Robotics , Sameed Tehami Electrical Engineering \& Information Technology at 2015 IEEE $21^{\text {st }}$ International Symposium for Design and Technology in Electronic Packaging (SIITME) .

3. Developing the control system of a syringe infusion pump published by R. Assunção, P. Barbosa, R. Ruge, P. S. Guimarães, J. Alves, I. Silva and M. A. Marques Physics Department, Polytechnic of Porto-School of Engineering, Porto, Portugal at 2014 11th International Conference on Remote Engineering and Virtual Instrumentation (REV) . 
4. Design of an Embedded Controller for next generation low cost Insulin Pump by Tom T Thomas, Asst. Professor S. Nithin and Asst.Professor P. Sivraj Department of EEE,Amrita School of Engineering, Coimbatore, Amrita Vishwa Vidyapeetham, India published at Proceedings of the International Conference on Inventive Research in Computing Applications (ICIRCA 2018)

5. A silicon-based MEMS vibrating mesh nebulizer for inhaled drug delivery by Oskar Z. Olszewski, Ronan MacLoughlin, Alan Blake, Mike O’Neill, Alan Mathewson, Nathan Jackson

Tyndall National Institute, University College Cork, Lee Maltings Complex, Dyke Parade, T12R5CP, Cork, Ireland Aerogen Ltd. Galway Business Park, Dangan, Galway, Ireland Analog Devices International, Raheen, Limerick, Ireland published at 2016 30th Eurosensors Conference.

\section{Author's details:}

1. Vasu S, PG scholar at GMIT Bharathi Nagar Maddur Tq, Mandya Dist, affiliated to Visvesvaraya Technological University Belagavi

2. Jithendra P R Nayak Assistant professor at GMIT Bharathi Nagar Maddur Tq, Mandya Dist, affiliated to Visvesvaraya Technological University Belagavi 